\title{
Change in Bone Mineral Density with Strontium Citrate: An Illusion or Reality
}

\author{
Faryal S Mirza*, Sidra Azim, Amit Bhargava \\ Division of Endocrinology, University of Connecticut Health Center, Farmington, CT
}

Received: August 13, 2016; Accepted: August 30, 2016; Published: September 13, 2016

*Corresponding author: Faryal S Mirza, MD, Division of Endocrinology, University of Connecticut Health Center, 263 Farmington Avenue, Farmington, CT 06030,Phone: 860-679-2000; Fax: 860 679-1258; Email: fmirza@uchc.edu

\begin{abstract}
We are seeing an increased use of Strontium Citrate (SrC) as a nutritional supplement in the US in the form of self-administration by patients to improve bone density. There are no current data available on the effectiveness and safety of SrC on bone. Strontium Ranelate $(\mathrm{SrR})$ is used to treat osteoporosis in Australia/Europe but is not FDA approved in the United States (US). Sr is a heavy element and when incorporated in the bone can cause overestimation of BMD. We report an increase in Bone Mineral Density (BMD) in three patients with osteoporosis who took over the counter SrC. After stopping $\mathrm{SrC}$, all of them were noted to have a significant decrease in BMD. These findings suggest that the increase in BMD with $\mathrm{SrC}$ may be a result of accumulation of $\mathrm{Sr}$ in the bone, and the decrease in BMD after its discontinuation may be related to lower Sr levels in bone. In the absence of data on the efficacy and safety of the effects of $\mathrm{SrC}$ on bone and the technical interference of Sr on BMD measurement, it may be safer to avoid using it. Further studies are needed to delineate the effect of $\mathrm{SrC}$ on bone health and safety.
\end{abstract}

Keywords: Osteoporosis; Strontium Citrate; Bone Mineral Density; Postmenopausal Women

\section{Background}

$55 \%$ of Americans older than 50 years of age have osteoporosis (OP), $80 \%$ being women [1]. More than 250,000 hip and wrist fractures and more than 750,000 vertebral fractures occur in the United States (US) annually due to OP [2]. Morbidity and mortality from fractures due to OP pose a significant financial burden on health care [3]. Majority of the treatments currently approved for OP in the United States (US) have anti-resorptive effects with teriparatide being the only agent with anabolic effects. Strontium Ranelate ( $\mathrm{SrR}$ ), another anabolic agent, is prescribed in $>70$ countries for post-menopausal OP but is not FDA approved in US. In the US, we are seeing an increasing trend to treat OP "naturally" among patients, with self-administration of Over The Counter (OTC) Strontium Citrate ( $\mathrm{SrC}$ ) despite a paucity of data to support its use. It is being promoted as a nutritional supplement for bone health. We report the changes in Bone Mineral Density (BMD) in 3 patients who self-administered $\mathrm{SrC}$ for several years, and the changes in BMD after discontinuation of SrC.

\section{Case 1}

76-years-old female with OP took alendronate weekly for 10 years till 2006, then every other week for another year and was initiated on a drug holiday. She started self-administrating $\mathrm{SrC}(680 \mathrm{mg} /$ day) in 2006 and continued to take daily calcium (600mg bid) and vitamin D (2000units). Serum calcium and Vitamin D (32-66ng/ml) remained normal. She continued SrC on her own till 2012, when she agreed to stop taking it due to concerns about accumulation and toxicity.

On Dual Energy X-ray absorptiometry (DEXA) scan, total hip mean BMD increased $2.7 \%$ in the first 2 years on $\mathrm{SrC}$ after stopping alendronate, and continued to increase to a maximum of $9.2 \%$ after 6 years of treatment with $\mathrm{SrC}$ (1.53\%/year). Lumbar Spine (LS) BMD was nondiagnostic due to degenerative changes in the spine. In the first 2 years off of $\mathrm{SrC}$, total hip mean BMD decreased by $5.7 \%$.

\section{Case 2}

64 year old female with history of osteoporosis, which was diagnosed in 2001. She took Actonel 35mg weekly for 5years, stopped for more than a year and resumed Actonel intermittently for another 2 years before starting drug holiday. She was taking Calcium $500 \mathrm{mg}$ in the multivitamin and $2500 \mathrm{mg}$ of vitamin D. Serum calcium and vitamin D were within normal range. She started strontium citrate $680 \mathrm{mg}$ daily in 2009 and took it for 5 years, stopping it in 2014.

Yearly assessment of her BMD via DEXA scan showed an increase of $4.3 \%$ at LS spine (L1-L4 vertebrae), and $7.6 \%$ at total hip within 1 year of SrC treatment. At 5 years, BMD increase was $6.5 \%$ at LS and $12 \%$ for mean total hip. She agreed to stop SrC at this time. 1 year after stopping SrC, LS BMD decreased by $9.1 \%$ and total hip BMD decreased by $4.2 \%$.

\section{Case 3}

59 year old female with OP was treated with weekly alendronate for 4 years till 2007, when she stopped it due to concerns for osteonecrosis of jaw. She was advised to resume alendronate in 2008 due to declining BMD, but opted not to take it. 
She started self-administration of $680 \mathrm{mg}$ of $\mathrm{SrC}$ daily in February 2009 and continued it for four years till January 2013, when she stopped it due to myalgias and concern about risk for toxicity. Due to her history of ulcerative colitis, she was limited in dairy intake although averaged half a cup of almond milk daily and took calcium supplements with the SrC preparation. Serum calcium and vitamin D were within normal range. BMD via DEXA scan showed an increase of $10.7 \%$ at LS (L1-L4) at 2 years after starting $\mathrm{SrC}$, and $4.3 \%$ at total hip. BMD decreased by $14 \%$ at LS and by $6.4 \%$ at total hip a year after stopping SrC.

\section{Discussion}

Strontium ( $\mathrm{Sr}$ ) is an alkaline earth element present in grains and seafood (range $0.3-5.0 \mathrm{mg} / \mathrm{kg}$ ) [4], and is similar to calcium in terms of absorption and incorporation into bone [5]. 25-30\% of $\mathrm{Sr}$ in diet is absorbed through the gastrointestinal tract and $99.1 \%$ of this is distributed in the mineralized tissue $[6,7]$. The whole-body strontium content of an average $(70 \mathrm{~kg})$ human is estimated at $320 \mathrm{mg}$ (approximately $0.0005 \%$ by weight).

Commonly available $\mathrm{Sr}$ formulations include Strontium Ranelate (SrR), which is approved for the treatment of OP in postmenopausal women in Europe, and Strontium Citrate ( $\mathrm{SrC})$, which is available Over The Counter (OTC) in US. Sr occurs naturally as mineral deposits of strontium sulfate and strontium carbonate. $\mathrm{SrC}$ is the chelated form of $\mathrm{Sr}$ and is made from strontium minerals and citrate. Strontium ranelate consists of a combination of strontium and ranelic acid. SrR is not approved for use in the US. Standard doses of SrR (2g) and SrC (1944mg) deliver $680 \mathrm{mg}$ of elemental Sr, twice the amount naturally present in the human body on a daily basis, or 170-340 times the naturally occurring strontium levels in the human diet per day. Over-the-counter supplements containing strontium citrate are available in the US, which is being widely self-administered by patients to improve bone density.

SrR has been shown in vivo and in vitro studies to simultaneously decrease bone resorption and increase bone formation $[7,8]$. SrR exerts antiresorptive effect by modulating $\mathrm{NF \kappa B}$ signaling pathway and decreasing osteoclast differentiation. It further causes apoptosis of osteoclast via Calcium Sensing Receptor (CaSR) activation and Protein kinase C $\beta$ II (PKC $\beta$ II) pathway [8] and regulates osteoclast activity by increased osteoprotegrin production and decreased Receptor Activator of Nuclear Factor kappa-B Ligand (RANKL) expression [9], resulting in decreased bone resorption. In addition, SrR also has anabolic effect on bone and increases replication, maturation and function of osteoblasts via Calcineurin/Nuclear Factor of Activated T-Cell (Cn/NFATc1), Extracellular_Signal-Regulated Kinases-Mitogen-Activated_Protein_kinases (ERK-MAPK) and Wnt signaling activation. In vitro studies show an increase in markers of osteogenesis including alkaline phosphatase, sclerostin, collagen, sialoprotein and osteocalcin $[8,9]$.

Histiomorphic and CT analyses of bone show improved bone mass, volume, microarchitecture and strength following SrR supplementation [7, 10-13]. Its effects are seen more on trabecular bone than cortical bone [9]. Bone apatite crystals quality is preserved after SrR use for 3 years [14], with Sr comprising $1 \%$ of the mineral content of the treated bone. Due to its high molecular weight, this $1 \%$ incorporation of $\mathrm{Sr}$ causes an average overestimation of BMD of $10 \%$ [15]. Following 10 years of SrR therapy, most of the $\mathrm{Sr}$ content in bone is still retained and slowly removed by bone resorption.

Several randomized, placebo controlled, double blind studies have been done to assess safety and efficacy of SrR. The STRATOS trial (Strontium Administration for Treatment of Osteoporosis) evaluated 353 women with OP and vertebral fractures, [16] and the DEXA Lumbar/femoral BMD showed a dose dependent improvement of bone density and a 56\% relative risk reduction (RR) of new vertebral fractures with $2 \mathrm{~g} / \mathrm{d}$ SrR. Similarly, SOTI trial (Spinal Osteoporosis Therapeutic Intervention) [17] and the TROPOS study (Treatment of Peripheral Osteoporosis) both also showed increase in BMD and reduction in fracture risk with SrR.

There are no human studies evaluating the change in BMD with $\mathrm{SrC}$. Much of the bone density increase being seen with $\mathrm{SrC}$ is likely due to the replacement of calcium with strontium in the bone. Strontium has a larger atomic weight than calcium $(38$ vs 20), which causes it to attenuate X-rays more strongly than calcium. Hence the readings on the DEXA scan appear artificially inflated with bone density looking better than is the case. Comparisons of Ca hydroxyapatite (natural bone crystal) and $\mathrm{Sr}$ hydroxyapatite (Sr-substituted bone crystal) have revealed that for every $1 \%$ of strontium incorporated into bone crystal, BMD is overestimated by $10 \%$ [18].

SrC and SrR are both vectors for Sr delivery. In a study comparing the effect of the administration of $\mathrm{SrC}$ and $\mathrm{SrR}$, utilizing an in vivo X-ray fluorescence spectroscopy (XRF) system to quantify bone strontium accumulation in female rats [19], Wohl et al found that at 8 weeks, both SrR and SrC were found to be equally efficacious at delivering $\mathrm{Sr}$ to bone. Moise et al. used the same technique (XRF) to measure Sr levels in an osteoporotic subject self-administering $\mathrm{SrC}$ at $680 \mathrm{mg} /$ day [20]. After $2 \frac{1}{2}$ years, Sr levels were shown to be 7 to 15 times greater than at baseline. Higher concentrations were seen in the ankle, and with incorporation of $\mathrm{Sr}$ in trabecular bone. Ankle Sr levels also did not seem to plateau within 2-3 years and continued to increase on supplementation.

In our subjects, we observed an average 8-10\% increase in BMD after self-administration of SrC for 4-6 years which is similar to what has been reported with $\operatorname{SrR}[15,17,21]$. It is unclear whether this increase in BMD is true or if it is an overestimation due to the increased attenuation of $\mathrm{x}$-rays due to the larger atomic weight of Sr. Follow up BMDs in our patients after discontinuing SrC show a significant decline in BMD, likely related to the reduced bone Sr content after discontinuation of SrC supplements.

The increase in BMD seen with Sr preparations over a period of time may even be much more than $10 \%$. In a reanalysis of the SOTI data, up to $75 \%$ of the BMD increase from strontium is an artifact [5]. The definitive way to accurately determine bone $\mathrm{Sr}$ content is by bone biopsy.

Strontium also remains in bones after treatment is discontinued, sometimes for extended periods of time. Six months after discontinuation of Sr treatment, bone Sr retention was over $70 \%$ in patients who had undergone the longest treatment (8y). 
Power curves have estimated that at the longest treatment times (8 years, 1\% total bone $\mathrm{Sr}$ ), bone $\mathrm{Sr}$ content would not return to baseline levels for 25 years [22]. Because of this relatively high $\mathrm{Sr}$ retention in bone, overestimation of BMD by DXA will continue at a variable rate for some time, which can potentially last for several years.

There are no data on safety of short term or long-term use of SrC. Previous studies have associated SrR with gastrointestinal disturbances, memory loss, an increased risk of developing venous thromboembolism, and allergic skin reactions such Stevens-Johnson Syndrome. European Medicines Agency (EMA) recommends restricting the use of SR, given concerns of an increase in cardiovascular events. Concerns have also been raised regarding the development of rickets and osteomalacia, due to $\mathrm{Sr}$ accumulation in renal failure. Sr induced mineralization defects have been seen in rats with renal insufficiency receiving moderate $\mathrm{Sr}$ supplementation $(2 \mathrm{~g} / \mathrm{l} ; 200 \mathrm{mg} / \mathrm{kg} /$ day $)$ over 12 weeks. This effect was reversed after strontium withdrawal over 8 weeks.

As calcium is used not only in bone but is also an important cellular signal in neurotransmitter release, muscle contraction and electrical conduction in the cardiac muscle. $\mathrm{SrC}$ may have adverse effects on these processes as well, which need to be studied further. Substitution of strontium for calcium is used to experimentally alter these processes, for example, to slow neurotransmitter release to study synaptic transmission [23]. In the absence of safety data, the known side effects with SrR, and the interference in BMD measurements with $\mathrm{Sr}$, it may be best to avoid self-administration of $\mathrm{SrC}$ as a nutritional supplement till more is known about its effects.

\section{Conclusion}

We report changes in BMD in three women self-administering OTC strontium citrate. There is an increased trend for selfadministration of $\mathrm{SrC}$ for $\mathrm{OP}$ in the US and paucity of data regarding the effect of SrC use on BMD and its safety. Clinicians need to be vigilant in asking their patients about $\mathrm{SrC}$ intake and checking the calcium supplements as $\mathrm{SrC}$ is being added to several over the counter calcium supplements as well.

\section{References}

1. National Osteoporosis Foundation. America's Bone Health: The State of Osteoporosis and Low Bone Mass in Our Nation Mass in Our Nation. Washington, DC: National Osteoporosis Foundation. 2002.

2. Riggs BL and LJ Melton 3rd. The worldwide problem of osteoporosis: insights afforded by epidemiology. Bone, 1995;17(5 Suppl):505S$511 \mathrm{~S}$

3. Cauley JA, Hochberg MC, Lui LY, Palermo L, Ensrud KE, Hillier $\mathrm{TA}$, et al. Long-term risk of incident vertebral fractures. JAMA 2007;298(23):2761-2767. doi: 10.1001/jama.298.23.2761.

4. Cashman KD. Diet, nutrition, and bone health. J Nutr. 2007;137(11 Suppl):2507S-2512S

5. Blake GM and I Fogelman. Strontium ranelate: a novel treatment for postmenopausal osteoporosis: a review of safety and efficacy. Clin Interv Aging. 2006;1(4):367-375.

6. Apostoaei AI. Absorption of strontium from the gastrointestinal tract into plasma in healthy human adults. Health Phys. 2002;83(1):56-65.

7. Boivin G, A Doublier and D Farlay. Strontium ranelate--a promising therapeutic principle in osteoporosis. J Trace Elem Med Biol 2012;26(2-3):153-156.

8. Saidak Z and PJ Marie. Strontium signaling: molecular mechanisms and therapeutic implications in osteoporosis. Pharmacol Ther. 2012;136(2):216-226. doi: 10.1016/j.pharmthera.2012.07.009

9. Marie PJ, D Felsenberg and ML Brandi. How strontium ranelate, via opposite effects on bone resorption and formation, prevents osteoporosis. Osteoporos Int. 2011;22(6):1659-1667. doi: 10.1007/ s00198-010-1369-0.

10. Arlot ME, Jiang Y, Genant HK, Zhao J, Burt-Pichat B, Roux JP, et al. Histomorphometric and microCT analysis of bone biopsies from postmenopausal osteoporotic women treated with strontium ranelate. J Bone Miner Res. 2008;23(2):215-222.

11. Rizzoli R, Laroche M, Krieg MA, Frieling I, Thomas T, Delmas P, et al., Strontium ranelate and alendronate have differing effects on distal tibia bone microstructure in women with osteoporosis. Rheumatol Int. 2010;30(10):1341-1348. doi: 10.1007/s00296-010-1542-y.

12. Jobke B, Andrew J Burghardt, Burkhard Muche, Michael Hahn, Jutta Semler, Michael Amling, et al. Trabecular reorganization in consecutive iliac crest biopsies when switching from bisphosphonate to strontium ranelate treatment. PLoS One. 2011;6(8):e23638.

13. Bain SD, Jerome C, Shen V, Dupin-Roger I, Ammann P. Strontium ranelate improves bone strength in ovariectomized rat by positively influencing bone resistance determinants. Osteoporos Int. 2009;20(8):1417-1428. doi: 10.1007/s00198-008-0815-8.

14. Doublier A, Farlay D, Jaurand X, Vera R, Boivin G. Effects of strontium on the quality of bone apatite crystals: a paired biopsy study in postmenopausal osteoporotic women. Osteoporos Int 2013;24(3):1079-1087. doi: 10.1007/s00198-012-2181-9

15. Blake GM. and I Fogelman. Long-term effect of strontium ranelate treatment on BMD. J Bone Miner Res. 2005;20(11):1901-1904.

16. Meunier PJ, Slosman DO, Delmas PD, Sebert JL, Brandi ML, Albanese $\mathrm{C}$, et al. Strontium ranelate: dose-dependent effects in established postmenopausal vertebral osteoporosis--a 2-year randomized placebo controlled trial. J Clin Endocrinol Metab. 2002;87(5):20602066.

17. Meunier PJ, Christian Roux, Ego Seeman, Sergio Ortolani, Janusz E Badurski, Tim D Spector, et al, The effects of strontium ranelate on the risk of vertebral fracture in women with postmenopausal osteoporosis. N Engl J Med. 2004;350(5):459-468. DOI: 10.1056/ NEJMoa022436

18. Blake GM and I Fogelman. The correction of BMD measurements for bone strontium content. J Clin Densitom. 2007;10(3):259-265.

19. Wohl GR, Chettle DR, Pejović-Milić A, Druchok C, Webber CE, Adachi JD, et al., Accumulation of bone strontium measured by in vivo XRF in rats supplemented with strontium citrate and strontium ranelate. Bone. 2013;52(1):63-69. doi: 10.1016/j.bone.2012.09.002.

20. Moise H, Adachi JD, Chettle DR, Pejović-Milić A. Monitoring bone strontium levels of an osteoporotic subject due to self-administration of strontium citrate with a novel diagnostic tool, in vivo XRF: a case study. Bone. 2012;51(1):93-97. doi: 10.1016/j.bone.2012.04.008.

21. Reginster JY, Seeman E, De Vernejoul MC, Adami S, Compston J, Phenekos C, et al. Strontium ranelate reduces the risk of nonvertebral fractures in postmenopausal women with osteoporosis: Treatment of Peripheral Osteoporosis (TROPOS) study. J Clin Endocrinol Metab. 2005;90(5):2816-2822.

22. Barenholdt O, N Kolthoff, and SP Nielsen. Effect of long-term treatment with strontium ranelate on bone strontium content. Bone. 2009;45(2):200-206.doi:10.1016/j.bone.2009.04.196.

23.Xu-Friedman MA and WG Regehr. Probing fundamental aspects of synaptic transmission with strontium. J Neurosci. 2000;20(12):44144422 